\title{
A inclusão de crianças com necessidades especiais nas aulas de Educação Física na educação infantil
}

\author{
Atos Prinz Falkenbach \\ Fernando Edi Chaves** \\ Dileni Penna Nunes*** \\ Vanessa Flores do Nascimento ${ }^{* * * *}$
}

\begin{abstract}
Resumo: O presente estudo investiga a temática da inclusão de crianças com necessidades especiais na prática pedagógica da Educação Física na Educação Infantil. A metodologia é de corte qualitativo, os participantes do estudo são professores de educação física da rede regular de ensino que possuem crianças com necessidades especiais nas suas aulas da educação infantil. A coleta de informações utilizou instrumentos como entrevistas e observações. Os resultados do estudo são apresentados em categorias: compreensão da inclusão na prática da educação física; experiências relacionais do professor com crianças com necessidades especiais; perspectivas de qualificação profissional; suporte pedagógico para o processo de inclusão. O estudo permite evidenciar que os professores de educação física reconhecem a inclusão como uma necessidade pedagógica, porém a formação continuada e a prática pedagógica carecem de aprendizagens e avanços nessa área.
\end{abstract}

Palavras-chave: Educação Física. Educação Infantil. Pessoas portadoras de deficiência. Aceitação social.

\section{INTRODUÇÃO}

O presente estudo, que aborda a prática pedagógica da educação física na escola sob o prisma da inclusão, parte da compreensão e da necessidade de investigar o processo de inclusão na ação pedagógica da educação física escolar na educação infantil.

A Educação Física é componente curricular e pedagógico obrigatório nas escolas de educação fundamental (BRASIL, 1996).

\footnotetext{
*Professor, Doutor. Centro Universitário Metodista IPA/UNIVATES. E-mail: atos@univates.br **Professor, Mestre. Centro Universitário Metodista IPA. E-mail: fernando.chaves@metodistadosul.edu.br

*** Bolsista de Iniciação Científica. IPA-Porto Alegre, RS. E-mail: dileninunes@yahoo.com.br **** Bolsista de Iniciação Científica. IPA-Porto Alegre, RS. E-mail: nessaflowers@yahoo.com.br
} 


\section{Astigos Origimais}

Atos Prinz Falkenbach, et al.

Portanto, a educação física também implica questões e avanços educacionais da escola; isso requer um entendimento que a prática da inclusão se refere à ação pedagógica da educação física também.

$\mathrm{O}$ ponto de partida para a justificativa do estudo parte do entendimento dos estudos atuais sobre a ação de inclusão na escola regular. A prática pedagógica escolar apresenta dificuldades acerca de entendimentos, aceitação e organização pedagógica para a finalidade da inclusão (KASSAR, 2005).

A educação física, caracterizada pela sua história voltada para uma prática seletiva, segregadora e técnica, pode ser compreendida como a área pedagógica da escola com menor tendência para as finalidades da inclusão. Tanto na educação física, como nas demais práticas da escola regular, a inclusão pode constituir-se em uma ação extremamente complexa aos professores e à comunidade escolar, uma vez que a ação pedagógica tem buscado a universalização e uniformização do conhecimento. Este aspecto impossibilita olhar para a individualidade e as relações entre as diferenças.

Sem a intenção de esgotar o universo de fatores acerca da problemática da inclusão escolar, ainda é possível destacar a distância dos projetos pedagógicos, suas articulações políticas e comunitárias na ação coletiva desta comunidade. Tal aspecto pode deixar o professor em situação de isolamento e sem apoio diante dessa nova realidade, dificultando sua atuação pedagógica com os alunos.

A partir desta introdução problematizadora da inclusão na prática pedagógica escolar, mais especificadamente da educação física, foi possível organizar a questão norteadora do estudo que é: como o professor de educação física recebe e atua com crianças com necessidades especiais em suas práticas pedagógicas?

São questões de investigação que se desdobram a partir da questão principal: a) Como o professor concebe a inclusão de crianças com necessidades especiais na prática da educação infantil? b) Que experiências o professor relata em sua atuação com a inclusão de crianças com necessidades especiais? c) Como percebe a organização da escola para o processo de inclusão de crianças com necessidades especiais?

Movimento, Porto Alegre, v.13, n. 02, p.37-53, maio/agosto de 2007. 
Sem a intenção de responder prontamente as questões organizadas, passamos a refletir argumentos teóricos da temática da inclusão de crianças com necessidades especiais na escola.

\section{PROBLEMATIZANDO A EDUCAÇÃO DA CRIANÇA COM NECESSIDADES ESPECIAIS}

A inclusão escolar é uma situação atual, muito diferente das concepções históricas acerca das necessidades especiais. As insuficiências corporais, além de modificarem as relações do ser humano com o mundo, se manifestam no comportamento diferenciado nas relações com as pessoas. Desde o meio familiar, a criança com necessidades especiais é tratada de maneira que se diferencia do habitual pela atenção e cuidados.

Vygotsky (1997) assinala que as deficiências provocam uma orientação social absolutamente particular. Essa alteração resulta, com grande frequiência, em alterações e perturbações sociais. Todas as organizações sociais, vínculos, referências, papel e destino são cortados pela influência de um tratamento social diferenciado desde a infância, no seio familiar e continuado na ação social. No âmbito educacional , essa problemática continua sendo social. A prática ainda segrega a criança com necessidades especiais na escola regular.

A prática e a literatura pedagógica científica se socorrem nos parâmetros estudados pela psicologia e a medicina, áreas do conhecimento que, no período inicial do século XX, difundiram a deficiência infantil caracterizando-a como um problema biológico, ou seja, as deficiências como estruturas predestinadas da personalidade e as suas relações com o mundo físico natural (PADILHA, 2001).

Vygotsky (1997) explica que o uso de diagnósticos como o histórico teste do quociente intelectual (QI) não reconhecia as proporções devastadoras da sua investida social. O componente educacional foi o mais prejudicado pelas rotulações e preconceitos desenvolvidos a partir de um nível de inteligência socialmente reconhecido como maior ou menor, mensurado em escalas de pontos.

Movimento, Porto Alegre, v.13, n. 02, p.37-53, maio/agosto de 2007. 
Movida por este comportamento padronizador de níveis de desenvolvimento, a escola de educação especial apresentou um modelo que buscou isolar cada vez mais as crianças das experiências coletivas e das relações diferentes. O sistema fechado de educação para diferentes necessidades especiais em grupos isolados serviu como um sistema atraente e amplamente divulgado. Tais escolas construíram um mundo isolado para os deficientes com trabalhos e estudos próprios, mas que serviram apenas para isolar e cada vez mais confirmar a idéia de que não se deve conviver junto.

Vygotsky (1997) compreende a escola com o seu próprio programa, metodologia, modo de vida escolar, com professores especializados e conscientes de um processo diferenciado. A ação educativa inclusiva nos moldes atuais é tarefa impossível, pois a vida escolar se comporta de forma excludente.

O problema das deficiências e do processo educativo se configura por não fazer parte somente do passado, mas do futuro, o que significa que esse problema é agora uma necessidade do presente. No terreno da educação, as deficiências requisitam um ambiente novo e criativo, um modo de vida escolar com organização de novas formas especiais de se envolver o aprendizado respeitando as características especiais.

O senso comum já reconhece que a criança normal pode conviver em sociedade, sendo que para as demais se reservam os centros, as associações, os asilos, as temidas clínicas de tratamento e outras denominações que conservam e controlam os comportamentos "anormais" (GOFFMAN, 2001). É importante entender que tais registros sobrecarregam a cultura humana do medo e da angústia de vir a ter ou de desenvolver uma criança com necessidades especiais.

\section{EDUCAÇÃO FÍSICA ESCOLAR DIANTE DA INCLUSÃO}

O termo "inclusão" é extremamente recente, data do ano de 1994 quando a UNESCO, por ocasião da Declaração de Salamanca, registrou sua denominação no âmbito da educação regular. Kassar (2005) explica que o termo requisita compreender as condições favoráveis e necessárias para receber, manter e promover com plenas

Movimento, Porto Alegre, v.13, n. 02, p.37-53, maio/agosto de 2007. 
competências as crianças com necessidades especiais, incluídas aquelas com necessidades especiais severas. Stöbaus e Mosquera (2005) explicam que a terminologia da inclusão, apesar de estar ganhando o reconhecimento por parte dos professores, a totalidade de sua dimensão carece de maiores detalhamentos em relação aos experimentos e estudos que atendam a abrangência da terminologia.

A prática pedagógica de caráter inclusivo na educação física esbarra em históricas dificuldades que estão relacionadas com o entendimento da sua ação. Enquanto a ação pedagógica estiver centrada no ensino do movimento e o desenvolvimento de sua técnica respaldada por conceitos de "melhor/pior", "certo/errado" e "ganhar/perder", sempre haverá margem para a exclusão.

Outro tópico problematizador para o aspecto da inclusão, citado por Stöbaus e Mosquera (2005), trata da formação dos professores, cujo processo careceu de estudos aprofundados e focados na temática. A legislação que aborda a temática da inclusão e das diferenças no processo formativo dos professores é um evento atual (BRASIL, 2002). Nesta perspectiva, podemos entender que toda a ação pedagógica dos professores para uma finalidade de inclusão está respaldada em um senso comum e de empirismo.

Duarte e Santos (2005) descrevem a ação de inclusão na área da educação física para além do simples desenvolvimento de atividades físicas. O papel do professor de educação física é de contribuir com uma formação de cidadão, cuja ação educativa é possibilitar aprendizagens e avanços nas capacidades de adaptação da criança com necessidades especiais e a sua vivência e relação corporal.

Quando a temática trata da ação pedagógica da educação física na educação infantil com vistas à inclusão, entendemos que o brincar ganha significância no papel de aprendizado da criança (FALKENBACH, 2005). O brincar capacita a experimentação concreta da criança, possibilitando um ir e vir entre as representações mentais e as ações concretas, firmando-se como um facilitador no exercício das aprendizagens.

Movimento, Porto Alegre, v.13, n. 02, p.37-53, maio/agosto de 2007. 


\section{Astifor Originais}

Atos Prinz Falkenbach, et al.

No que diz respeito às aproximações com a inclusão, o brincar coletivo permite constituir um exercício claro de trocas e de comunicação. O brincar como linguagem universal, favorece relações profundas e consistentes entre as crianças (WINNICOTT, 1975).

Vygotsky (1997) defende a coletividade como estímulo para o desenvolvimento baseado nas formas coletivas de colaboração precedem as formas individuais de conduta, que crescem sobre as suas bases constituindo-se suas progenitoras diretas e as fontes de sua origem.

O componente social é o fundamento para o avanço de novas possibilidades das crianças com necessidades especiais. Vygotsky (1997) explica que um dos fatores centrais do desenvolvimento cultural infantil é a colaboração, sendo a coletividade o fator de desenvolvimento das funções psíquicas superiores. No entanto a criança está, em geral, excluída da coletividade infantil. A linha de desenvolvimento dessa criança se torna lenta e o seu avanço tropeça em dificuldades derivadas de suas necessidades especiais. Assim se determinam formas inferiores de colaboração com outras crianças e, também, o desenvolvimento incompleto da conduta social e das funções psico-intelectuais que se estruturam no curso desse desenvolvimento.

\section{MEDOLOGIA DO ESTUDO}

O estudo desenvolvidoé de cunho qualitativo, em nível descritivo, e pretendeu investigar a ação educativa dos professores de educação física na tarefa de inclusão de crianças com necessidades especiais na prática regular da educação física. Pela sua natureza hermenêutica se ajusta às características do modelo qualitativo de investigação, como descreve Molina (1999) uma microetnografia, no que diz respeito ao presente estudo se trata de um estudo de casos.

Tomando como base os estudos de Gómez, Flores e Jiménez (1996) que assinalam a necessidade de critérios na elegibilidade dos contextos e participantes em estudos qualitativos, destacamos

Movimento, Porto Alegre, v.13, n. 02, p.37-53, maio/agosto de 2007. 
que as escolhas das escolas e professores participantes estiveram em acordo com alguns critérios, que são:

a) possuir a disciplina de educação física ministrada com regularidade semanal;

b) possuir professor com a devida habilitação para essa finalidade e que está presente como professor ministrante das aulas de educação física na escola;

c) a presença de, pelo menos, uma criança com necessidades especiais ${ }^{1}$ regularmente matriculada na turma de crianças que possui prática regular da disciplina de educação física.

Os participantes do estudo foram seis professores de educação física da rede regular de ensino e que possuem em suas aulas a presença regular de crianças com necessidades especiais: três professores da rede particular de ensino e três professores da rede municipal de ensino.

Foram utilizados os seguintes instrumentos durante o processo de coleta das informações:

- observações com pautas previamente definidas - como um recurso que permitiu visualizar e identificar o andamento da prática, de acordo com as questões de investigação já descritas na justificativa do presente artigo;

- entrevista semi-estruturada com os professores de educação física relacionadas ao desenvolvimento das observações.

O processo de coleta de informações foi analisado a partir do procedimento de triangulação das informações que, de acordo com Triviños (1995), permite maior fidedignidade na análise e interpretação dos resultados. O procedimento de triangulação possibilitou evidências precisas por intermédio do cruzamento das informações obtidas na coleta do estudo.

\footnotetext{
${ }^{1}$ Crianças com necessidades especiais podem ser crianças com deficiências físicas e/ou mentais, bem como necessidades educacionais mediante laudo técnico da orientação ou direção escolar.

Movimento, Porto Alegre, v.13, n. 02, p.37-53, maio/agosto de 2007.
} 


\section{Astigos Originais}

Atos Prinz Falkenbach, et al.

A análise e interpretação do processo de coleta de informações permitiu a organização das seguintes categorias: compreensão da inclusão na prática da educação física; experiências relacionais do professor com crianças com necessidades especiais; perspectivas de qualificação profissional nessa área; suporte pedagógico para o processo de inclusão.

As categorias organizadas se constituem no produto do desenvolvimento da investigação e serão descritas refletindo o referencial teórico do estudo em conjunto aos respectivos conteúdos obtidos nas informações coletadas.

\section{PROFESSOR DE EDUCAÇÃO FÍSICA E O TEMA DA INCLUSÃO}

O processo de investigação acerca do tema da inclusão na área da educação física demonstrou que o conhecimento ainda carece de compreensões claras e precisas da parte dos professores. Tal aspecto é compreensivo, uma vez que o termo "inclusão" também é recente na área educacional. A palavra dos professores sobre a inclusão de crianças com necessidades especiais expressa a ambigüidade e falta de clareza a que o termo remete quando trata da ação prática na educação física:

Depende de vários fatores, um é o tipo de necessidade da criança e o outro é o preparo dos professores para atenderem a esses alunos, para mim esses são os dois fatores fundamentais para saber da validade dessa inclusão. (Ent. n.5 em 25/11/2005).

Outro professor entrevistado relata o que segue:

Tem diferenças entre o colégio público e o particular. No particular é válido porque todos ajudam, todos os coleguinhas se preocupam com ele e por isso aprende bem mais com pessoas diferentes. No colégio público acho que os professores não se preocupam em ajudar, não trabalham com vontade. Na educação física, por mais que ele não toque na bola, é um momento que ele tem aqui de se comunicar com as outras crianças e participar de brincadeiras da sua forma, isso fora da escola provavelmente não deve acontecer. (Ent. n.2 em 16/11/2005).

Movimento, Porto Alegre, v.13, n. 02, p.37-53, maio/agosto de 2007. 
A compreensão acerca da inclusão na educação física, segundo os professores entrevistados, está na dependência de fatores como a formação de professores, na categoria da instituição educacional e também do nível das necessidades especiais das crianças.

É plenamente compreensível a necessidade de qualificação docente para o processo de inclusão na educação física. Porém, as compreensões permitem entender que a inclusão de crianças com necessidades especiais na prática da educação física também não é para todos, bem como a sua ação está condicionada às possibilidades de melhor saúde e melhor condição econômica daqueles com necessidades especiais. Esse fato permite compreender que a histórica prática de segregação ainda se mantém latente e distorce a concepção de inclusão.

\section{EXPERIÊNCIAS RELACIONAIS DO PROFESSOR COM CRIANÇAS COM NECESSIDADES ESPECIAIS}

As experiências dos professores com crianças com necessidades especiais na prática educativa regular da educação física são diversificadas e podem ser exemplificadas nos relatos das experiências que descrevem:

Minha experiência com essas crianças foi pouca. Foi com uma menina que tem hidrocefalia e outros comprometimentos. Ela participava eventualmente em algumas atividades de sensibilização. (Ent. n .5 em 25/11/2005)

Minhas experiências com crianças com necessidades especiais na educação física é restrita, sempre foram boas, tenho carinho pelas crianças, o problema era que a participação em aula desses era rara. (Ent. n.6 em 29/11/2005)

A participação eventual das crianças com necessidades especiais nas aulas de educação física é uma constante na fala dos professores entrevistados. Os isolamentos e situações impeditivas como as condições do tempo, as modalidades práticas e a falta da criança na aula são algumas dificuldades que prejudicam a participação em aula. Outro professor relata o que segue:

Movimento, Porto Alegre, v.13, n. 02, p.37-53, maio/agosto de 2007. 


\section{Astigos Origimais}

Atos Prinz Falkenbach, et al.

Há uma criança com nove anos de idade com deficiência mental, está em cadeira de rodas. Ela regrediu bastante e ano que vem vai para uma escola especial, pois é o terceiro ano que ela está no jardim e não pode ficar mais de dois anos retida na mesma turma (Ent. n.7 em 29/11/2005)

Em outro relato também está apresentada uma experiência de dificuldade:

Tive momentos difíceis com o menino com deficiência mental, ele não respondia nenhuma atividade proposta. Esse menino se excluía da aula e tinha vezes que sumia. A turma brincava na praça e eu tinha que deixar a turma para ir atrás dele (Ent. n.6 em 29/11/2005)

Podemos interpretar que a participação da criança com necessidades especiais na educação física escolar não depende da "boa vontade" de professores considerados "heróis" em sua atividade. Kassar (2005) destaca que a ação educativa de inclusão é responsabilidade institucional que deve prover condições para o processo da inclusão, diferente de uma ação isolada, centrada apenas no professor.

Outro professor de escola particular descreve o que segue:

A minha relação com o menino com síndrome de Down é tranqüila, gosto dele. Tenho que estar sempre atenta, porque a todo o momento ele faz alguma coisa errada. É a primeira vez que tenho experiência com crianças com necessidades especiais. É positivo, pois ele supera as expectativas, enfrenta os obstáculos como, por exemplo: cambalhotas que envolve coordenação, que eu penso que ele não conseguiria fazer. A única coisa que eu acho negativa é o fato de agredir os coleguinhas. (Ent. n.9 em 30/11/2005).

As observações realizadas nas aulas dessa professora indicam que o menino participa ativamente das aulas. Porém, as observações permitiram destacar que o menino pouco recebe atenção dos pares em situações de jogos coletivos. Receber passes no jogo de futebol não está nos planos dos colegas, nem da professora cuja ação pedagógica não prevê orientações para essa finalidade.

Movimento, Porto Alegre, v.13, n. 02, p.37-53, maio/agosto de 2007. 
O cuidado com o comportamento do menino é uma constante, mas pouco é dedicado aos avanços relacionais nas práticas coletivas.

\section{PERSPECTIVAS DE QUALIFICAÇÃO PROFISSIONAL DOS PROFESSORES PARAA INCLUSÃO}

A qualificação profissional para a questão da inclusão na escola é uma necessidade atual dos professores. A página eletrônica do Ministério da Educação e da Cultura mantém a Secretaria de Educação Continuada, Alfabetização e Diversidade, que atende as questões da diversidade e inclusão educacional, bem como o portal da Secretaria de Educação Especial, cujas ações são justamente a busca de promover a qualificação dos professores para a inclusão na escola.

Há o reconhecimento de que a formação superior dos Cursos promoveram as discussões, reflexões e práticas formativas para as necessidades especiais e a temática da inclusão. É nesse sentido que os professores entrevistados comentam suas perspectivas de formação e profissionais nessa área:

Eu não sou uma professora preparada para lidar
com essas crianças, não obtive essa formação. Não
me importo, apoio a inclusão e faço a inclusão. A
escola deveria oferecer melhores condições e
profissionais habilitados para essa finalidade. (Ent.
n.1 em 09/11/2005)

Outro professor entrevistado relata: "Fiz uma disciplina em minha formação acadêmica, li polígrafos que foram fornecidos em aula. Particularmente não vou em busca deste assunto" (Ent. n.2 em 16/11/2005).

Os professores entrevistados são unânimes em destacar a formação restrita nessa área. Percebemos que esse é um aspecto que, se por um lado lhes fragiliza e lhes traz certa indignação, por outro lado é utilizado como um escudo de defesa que evita maiores comprometimentos com a situação das crianças com necessidades especiais que estão na turma regular das crianças.

Nessa perspectiva, o professor é relevado à condição de estar fazendo uma ação educativa além de seu alcance de formação e isso

Movimento, Porto Alegre, v.13, n. 02, p.37-53, maio/agosto de 2007. 


\title{
48 Astifor Originais
}

Atos Prinz Falkenbach, et al.

permite com que faça uma avaliação que sempre o favorecerá, tal como: a) se a prática está sendo negativa e difícil, é porque não obteve formação para essa finalidade; b) se a prática está sendo um sucesso e possibilita a inclusão, então, o professor é elevado à condição de herói.

Independentemente da formação para essa finalidade, pudemos perceber que os professores pouco buscam subsídios que possam qualificar sua ação pedagógica. Pudemos identificar a inexistência de ações sistemáticas e regulares que possam fornecer um suporte pedagógico de conjunto ao professor. O continuismo dessa perspectiva possibilita espaços para manifestações de heroísmos ou de desculpas que se baseiam em uma ação cuja formação não lhe foi proporcionada.

\section{SUPORTE PEDAGÓGICO PARA O PROCESSO DE INCLUSÃO}

A categoria de análise que aborda as informações acerca do suporte pedagógico para o processo de inclusão abrange o apoio pedagógico que o professor de educação física recebe na escola, bem como a sua compreensão de como isso deve ser desenvolvido. Nesta categoria de análise, pudemos destacar duas unidades que são: a estrutura física da escola e a contínua qualificação dos recursos humanos.

Em relação à estrutura física da escola, é destacado que:

\begin{abstract}
A escola aceita crianças com necessidades especiais e possui a idéia de incluir. Mas faltam muitas coisas, isso significa projetos que não são aplicados por falta de espaço físico como rampas, banheiros, diminuir número de escadas na escola (Ent. n.1 em 09/11/2005).
\end{abstract}

\begin{abstract}
O menino somente consegue participar e vir para a aula por causa da sua mãe. Quando há chuva não conseguimos ajudar e não vem para a escola. Há uma subida muito acentuada e dificulta para a mãe dele trazer quando chove. (Ent. n.6 em 29/11/2005).
\end{abstract}

Tanto na escola da rede particular como na rede municipal, o interesse e a disponibilidade da filosofia da escola para incluir

Movimento, Porto Alegre, v.13, n. 02, p.37-53, maio/agosto de 2007. 
crianças com necessidades especiais está presente. Porém, a disponibilidade exercida na filosofia da escola esbarra nas estruturas físicas e nas condições para esse exercício. Outro aspecto dificultador para o exercício da inclusão nas escolas são os recursos humanos e pedagógicos:

Faltam profissionais que possam atender as crianças na qualidade de assistentes do professor de educação física. A escola deve oferecer profissionais como fonoaudiólogos como reforço para esses alunos. (Ent. n.1 em 09/11/2005).

A escola possui monitores de pedagogia especial para cada aluno com necessidades especiais, mas não são preparados porque são apenas do segundo semestre. Ajudam nos atendimentos básicos como carregar, levantar, estarem atentos às necessidades desse aluno. Eles não fazem nenhum trabalho específico, mas mesmo assim são de grande ajuda para mim. (Ent. n.5 em 25/11/2005).

Podemos compreender que a prática pedagógica já demonstra inclinação e uma tímida preparação para a finalidade da inclusão de crianças com necessidades especiais na educação física e isso é um excelente aspecto. Resta à escola a sua preparação sistemática e de manutenção de permanente qualificação e incentivos pedagógicos aos professores (GÓES, 2005). Também Negrine (2004) explica que os professores de educação física não podem estar sozinhos na tarefa pedagógica da inclusão. A prática pedagógica com crianças com necessidades especiais requer um amplo e preciso acompanhamento da evolução do grupo. Não basta apenas incluir a criança com necessidades especiais, é necessário prover recursos para sua manutenção. Neste aspecto, toda a escola está implicada em discussões sistemáticas para isso.

\section{CONSIDERAÇÕES FINAIS}

Estudar a temática da inclusão de crianças com necessidades especiais na prática da educação física da educação infantil é introduzir-se em um espaço que ainda dá os seus primeiros passos rumo à qualificação nesse processo. Descrevemos assim porque já percebemos compreensões de sensibilidade em relação ao tema da

Movimento, Porto Alegre, v.13, n. 02, p.37-53, maio/agosto de 2007. 


\section{Astigos Origimais}

Atos Prinz Falkenbach, et al.

inclusão, bem como já são manifestadas experiências que permitem aos professores pensarem nessa perspectiva.

A compreensão dos professores de educação física investigados permite compreender que ainda há aspectos a serem esclarecidos acerca da inclusão na sua prática pedagógica. Os professores, ao mesmo tempo em que se mostram favoráveis à inclusão, deixam claro suas restrições em relação a como deve ser feita. Os professores ainda mantêm a idéia de que há algumas necessidades especiais que podem estar na prática regular e outras que não podem.

Entendemos que esse aspecto é totalmente compreensível e que precisa avançar. Mas é um discurso muito diferente da educação física excludente e segregadora que guarda resquícios no pensamento e na ação dos professores de educação física. O pensamento é o primeiro aspecto a mudar e precisa ser continuadamente qualificado e refletido.

As experiências relacionais dos professores participantes do estudo destacam uma boa relação nas aulas de educação física. Essa relação está amparada em esforços dos professores para possibilitar à criança sua participação nas aulas. O fato que é destacado nesse processo é de os professores atuarem com base em experiências pessoais ou com base em seus conhecimentos prévios acerca das necessidades especiais. Podemos entender que tanto a formação inicial como a formação continuada dos professores não se ocupa de estudos sistemáticos acerca da prática pedagógica da educação física que inclui crianças com necessidades especiais.

Finalmente desejamos refletir essas considerações finais à luz do referencial teórico de Vygotsky (1997), que ensina que antes de buscar saber que necessidades especiais a criança possui, é necessário saber que criança possui necessidades especiais. É a partir dessa compreensão que podemos destacar que a escola é o ambiente que pode favorecer possibilidades para a criança, independente de suas necessidades especiais. Os professores de educação física podem ser capacitados para potencializar as capacidades da criança. É nessa perspectiva que a escola em sua totalidade pode prover um ambiente propício à criança com necessidades especiais.

Movimento, Porto Alegre, v.13, n. 02, p.37-53, maio/agosto de 2007. 
The inclusion of children with special needs on physical education classes at elementary school Abstract: The current research has investigated the inclusion of children with special needs in the pedagogical practice of Physical Education in elementary school. The methodology is qualitative, the subjects involved in the analysis work as Physical Education teachers in the regular school system and they deal with children with special needs in their classes. The data are composed by interviews and observations. The results are divided into four categories: comprehension of inclusion in the practice of Physical Education; the relation between teachers and children with special needs; prospects in the professional development; pedagogical support to the process of inclusion. This study has showed that Physical Education teachers recognize that inclusion is an important issue in the pedagogical practice. It also has showed that teachers' continuous formation and their pedagogical practice must be developed. Keywords: Physical Education. Child rearing. Disabled persons. Social Desirability.

\footnotetext{
La inclusión de niños con necesidades especiales en clases de educación física en la educación infantil. Resumen: El presente estudio investiga la temática de la inclusión social de niños con necesidades en la práctica pedagógica de la Educación Física en la educación infantil. La metodología utilizada en este trabajo es cualitativa, y los participantes son profesores de la red regular de la enseñanza que abarca niños con necesidades especiales. La búsqueda por informaciones ocurrió a través de los siguientes instrumentos: entrevistas y observaciones. Los resultados del estudio son presentados en categorías: comprensión de la inclusión en la práctica de educación física; experiencias relacionales del profesor con niños con necesidades especiales; perspectivas de calificación profesional; soporte pedagógico para el desarrollo de la inclusión. El estudio muestra que los profesores de educación física reconocen la inclusión como una necesidad pedagógica, sin embargo hace falta una formación progresiva, y la práctica de enseñanza con más aprendizaje y avanzos.

Palabras clave: Educación Física. Crianza del niño. Personas con discapacidad. Aceptación social.
}

Movimento, Porto Alegre, v.13, n. 02, p.37-53, maio/agosto de 2007. 


\section{REFERÊNCIAS}

BRASIL. Lei de Diretrizes e Bases da Educação Nacional. Brasília, 1996.

DUARTE, E. e LIMA, S. M. Atividade física para pessoas com necessidades especiais: experiências e intervenções pedagógicas. Rio de Janeiro: Guanabara Koogan, 2005.

FALKENBACH, A. Crianças com crianças na psicomotricidade relacional. Lajeado: UNIVATES, 2005.

GÓES, M. C. R. Desafios da inclusão de alunos especiais: a escolarização do aprendiz e sua constituição como pessoa. In: GÓES, M. C. R.; LAPLANE, A. L. F. Políticas e práticas de educação inclusiva. Campinas, SP: Autores Associados, 2005. p. 69-91.

GOFFMAN, E. Manicômios, prisões e conventos. São Paulo: Perspectiva, 2001.

GÓMEZ, G. R.; FLORES, J. G.; JIMÉNEZ, E. G. Metodología de la investigación cualitativa. Archidona: Aljibe, 1996.

KASSAR, M. C. M. Matrículas de crianças com necessidades educacionais especiais na rede de ensino regular: do que e de quem se fala? In: GÓES, M. C. R.; LAPLANE, A. L. F. Políticas e práticas de educação inclusiva. Campinas, SP: Autores Associados, 2005. p. 49-68.

MOLINA, R. M. O enfoque teórico metodológico qualitativo e o estudo de caso: uma reflexão introdutória. In: MOLINA NETO, V.; TRIVIÑOS, A. A pesquisa qualitativa na Educação Física: alternativas metodológicas. Porto Alegre: UFRGS, 1999. p. 95-105.

NEGRINE, A. S.; MACHADO, M. L. Autismo infantil e terapia psicomotriz: estudo de casos. Caxias do Sul, RS: EDUCS, 2004.

PADILHA, A. M. L. Práticas pedagógicas na educação especial: a capacidade de significar o mundo e a inserção cultural do deficiente mental. São Paulo: Autores Associados, 2001.

STÖBAUS, C. D.; MOSQUERA, J. M. Ideários da educação especial através de depoimentos de professores e seus alunos. In: RODRIGUES, D.; KREBS, R.; FREITAS, S. N. Educação inclusiva e necessidades educacionais especiais. Santa Maria: EDUFSM, 2005. p. 113-134.

TRIVIÑOS, A. N. S. Introdução à pesquisa em ciências sociais: a pesquisa qualitativa em educação. São Paulo: Atlas, 1995.

Movimento, Porto Alegre, v.13, n. 02, p.37-53, maio/agosto de 2007. 
VYGOTSKY, L. S. Obras Escogidas: fundamentos de defectología. Madrid: Visor, 1997. v.5.

WINNICOTT, D. W. O brincar e a realidade. São Paulo: Ímago, 1975.

Recebido em: 30/06/2006

Aprovado em: $02 / 05 / 2007$

Movimento, Porto Alegre, v.13, n. 02, p.37-53, maio/agosto de 2007. 